\title{
O QUE MUDOU PARA A POPULAÇÃO NEGRA NO ACESSO À EDUCAÇÃO BRASILEIRA? QUAIS OS (NOVOS) DESAFIOS?
}

\author{
Amélia Artes ${ }^{1}$
}

Danielle Oliveira ${ }^{2}$

Resumo: Este texto procura traçar uma linha histórica entre dois momentos: 1987 e a publicação do Cadernos de Pesquisa n. 63, da Fundação Carlos Chagas, que debateu a situação do Negro e a Educação, e a comemoração de 30 anos da publicação com a realização do Seminário Raça Negra e Educação: 30 anos depois - E agora do que mais precisamos falar? Se, em 1986, as discussões, a partir dos estudos quantitativos disponíveis na época, estavam centradas no não acesso dos negros aos anos iniciais da educação básica; passados 30 anos, os debates estão no acesso (ou, ainda, não acesso) de negros às etapas mais elevadas da educação: finalização do ensino médio e ingresso ao ensino superior. O que mudou nesse quadro? Se as consequências de racismo ainda estão presentes nos espaços sociais e de forma marcada, nas escolas; a visibilização das desigualdades contribui para a alteração de um quadro ainda preocupante: apesar de ser metade da população brasileira, os negros não chegam a $35 \%$ dos discentes no ensino superior. Apresenta os resultados a partir dos marcadores sociais de gênero e cor/raça, indicando que a interserccionalidade na construção das desigualdades que marcam a sociedade brasileira deve ser objeto de reflexão para a superação de uma realidade persistente.

Palavras-chave: Acesso; Negros; Gênero.

\section{WHAT HAS CHANGED FOR THE BLACK POPULATION IN TERMS OF ACCESS TO THE BRAZILIAN EDUCATIONAL SYSTEM? WHAT ARE THE (NEW) CHALLENGES?}

\begin{abstract}
This text seeks to draw a historical line between two moments: 1987 and the publication of Cadernos de Pesquisa n. 63, Carlos Chagas Foundation, which discussed the situation of the Black Citizen and Education, and the celebration of 30 years of the publication that culminated into holding the seminar Black Race and Education: 30 years later - And now what else do we need to talk about? If, in 1986, the discussions, based on the quantitative studies available at the time, were focused on the non-access of blacks to the initial stages of basic education, 30 years later the debates are around the access (or not) of blacks to the highest stages of education: completion of high school and admission to higher education. What has changed in this picture? If the consequences of racism are still present in society and markedly, in schools, the visibility of inequalities contributes to the alteration of a still worrying picture: despite comprising half of the Brazilian population, blacks do not reach $35 \%$ of the students in higher education. The study presents the results from the social markers of gender and color / race, indicating that the intersectionality in the construction of the inequalities that mark the Brazilian society must be object of reflection for the overcoming of a persistent reality.
\end{abstract}

Key-words: Access; Blacks; Gender.

\footnotetext{
${ }^{1}$ Doutora em Educação pela Universidade de São Paulo. Pesquisadora Fundação Carlos Chagas (FCC). E-mail: a.artes@gmail.com

${ }^{2}$ Mestranda em Sociologia no Instituto de Filosofia e Ciências Humanas na Universidade de Campinas (UNICAMP).E-mail: danielle.regina.o@gmail.com
} 


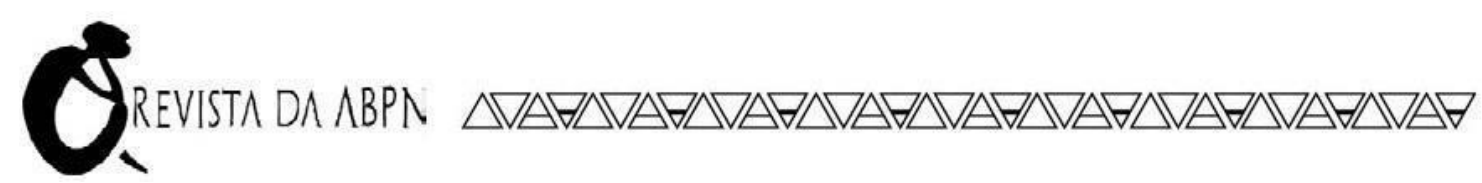

QU'EST-CE QUI A CHANGÉ AU BRÉSIL CONCERNANT L'ACCÈS DE LA POPULATION NOIRE À L'ÉDUCATION? QUELS SONT LES (NOUVEAUX) DÉFIS?

Résumé: Ce travail vise à tracer une ligne historique entre deux moments : 1987, date de la parution du 63e exemplaire de Cadernos de Pesquisa de la Fondation Carlos Chagas, dont le thème aborde les conditions des noirs dans l'éducation, et la commémoration des 30 ans de cette publication avec la tenue du séminaire Race noire et Éducation : 30 ans après - De quoi d'autre avons-nous besoin de parler ? Si, en 1986, les discussions basées sur les études quantitatives disponibles à l'époque mettaient en avant le non accès des élèves noirs aux premiers niveaux de l'enseignement élémentaire et du collège ; 30 ans plus tard, les débats concernent l'accès (ou le non accès) des élèves noirs aux niveaux plus élevés de l'enseignement : conclusion des études secondaires et admission à l'enseignement supérieur. Qu'est-ce qui a changé dans ce cadre ? Si les conséquences du racisme sont encore présentes dans les espaces sociaux et, de manière marquée, dans les écoles, la mise en visibilité des inégalités contribue au changement d'une situation encore alarmante : en effet, bien que constituant la moitié de la population brésilienne, les noirs représentent moins de $35 \%$ des étudiants de l'enseignement supérieur. Les résultats de cette étude sont présentés à partir des marqueurs sociaux de genre, de couleur et de race qui indiquent que, dans la construction des inégalités inhérentes à la société brésilienne, l'intersectionnalité doit faire l'objet d'une réflexion plus poussée visant à surmonter une réalité persistante.

Mots-clés: Accès; Noirs; Genre.

\section{¿QUÉ HA CAMBIADO PARA LA POBLACIÓN NEGRA EN TÉRMINOS DE ACCESO A LA EDUCACIÓN BRASILEÑA? ¿CUÁLES SON LOS NUEVOS DESAFÍOS?}

Resumen: Este texto busca trazar una línea histórica entre dos momentos: 1987 y la publicación de los Cuadernos de Investigación n. 63 de la Fundación Carlos Chagas, que debatió la situación del Negro y la Educación, y la conmemoración de 30 años de la publicación con la realización del Seminario Raza Negra y Educación: 30 años después - ¿Y ahora qué más necesitamos hablar? Si en 1986 las discusiones, a partir de los estudios cuantitativos disponibles en la época, estaban centradas en el acceso de los negros a los años iniciales de la educación básica, 30 años después los debates están en el acceso (o, aún, en el no acceso) de los negros a las etapas más elevadas de la educación: finalización de la enseñanza media y ingreso a la enseñanza superior. ¿Qué ha cambiado en este cuadro? Si las consecuencias del racismo todavía están presentes en los espacios sociales, y de forma marcada en las escuelas, la visibilidad de las desigualdades contribuye a la alteración de un cuadro aún preocupante: a pesar de ser la mitad de la población brasileña, los negros no llegan al 35\% de los discentes en la enseñanza superior. El estudio presenta los resultados de los grupos sociales de género y de color / raza, señalando que la interseccionalidad en la construcción de las inequidades que marcan la sociedad brasileña debe ser objeto de reflexión para el futuro de la persistente realidad.

Palabras-clave: Acceso; Negros; Género.

\section{ONDE TUDO COMEÇOU}

Em agosto de 1986, a Fundação Carlos Chagas (FCC) finalizou a versão preliminar do relatório "Diagnóstico sobre a situação educacional de negros (pretos e 
pardos) $)^{3}$ no estado de São Paulo"4. A solicitação fora feita pelo Conselho de Participação e Desenvolvimento da Comunidade Negra de São Paulo, na figura da Profa. Rachel de Oliveira, a partir da necessidade de se conhecer, discutir e dimensionar a situação dos alunos e alunas negras nas escolas do estado de São Paulo. O estudo, financiado com recursos da Fundação Ford, era composto de três partes:

1. A educação de negros através da bibliografia (disponível à época);

2. Preconceitos e discriminações raciais em livros didáticos e infanto-juvenis;

3. Indicadores educacionais.

Em dezembro do mesmo ano ${ }^{5}$ foi realizada, na sede da FCC, em São Paulo, o seminário com o tema $O$ Negro e a Educação, para a apresentação dos resultados do estudo realizado e discussões da temática racial com a participação de intelectuais, acadêmicos e ativistas e a presença de representantes do Movimento Negro ${ }^{6}$. Passados 30 anos, esse seminário é identificado como um marco na consolidação das temáticas raciais na educação e como espaço de denúncia dos preconceitos raciais vivenciados pelos negros e negras nos espaços escolares.

Fruto do seminário, em novembro de 1987, a revista Cadernos de Pesquisa, da FCC, publica um número especial, n. 63, com 22 artigos organizados em quatro módulos (Diagnóstico: análise de dados e do sistema escolar; Processo de socialização da criança e formação da identidade; Currículo: propostas e experiências de implantação; Livro didático: análises e propostas), acompanhada das transcrições dos debates realizados em cada uma das mesas do seminário de 1986. Compõem a publicação, ainda, 16 textos que reproduziram relato e avaliação de experiências educacionais que trouxeram para o evento as mais diversas formas de experiências

\footnotetext{
${ }^{3}$ Neste estudo o somatório de valores encontrados para pretos e pardos e apresentado na categoria negros. Baseia-se no conceito de raça, conforme descrito por Guimarães (2002), para quem raça é uma categoria socialmente constituída.

${ }^{4}$ A equipe era coordenada por Fúlvia Rosemberg e composta por Regina Pahim Pinto, Esmeralda V. Negrão, Cleide Perpetua Andrade e Lucia Lopes Barbieri.

${ }^{5} \mathrm{O}$ seminário foi realizado nos dias 3, 4 e 5 de dezembro de 1986.

${ }^{6} \mathrm{O}$ termo "Movimento Negro" apesar de estar no singular não condiz em admitir que as lutas antirracistas são homogêneas ou um bloco monolítico. De acordo com Lélia Gonzalez ( Hasenbalg e Gonzales1982) a definição deste termo se relaciona com o fato de que "Movimento Negro" representa a especificidade de suas lutas terem como cerne o negro. Contudo, há movimentos negros que formam o Movimento Negro, com uma complexidade de ações e demandas políticas.
} 
educacionais desenvolvidas por entidades e grupos negros em todas as regiões do Brasil.

Passados 30 anos e por iniciativa do Prof. Cleber Santos Vieira, da Universidade Federal de São Paulo (Unifesp), campus Guarulhos, surgiu a proposta de organizar uma nova publicação que avaliasse os percursos, avanços e desafios da temática Raça Negra e Educação nos tempos atuais. A parceria foi consolidada com a participação de representantes da $\mathrm{FCC}^{7}$, Unifesp ${ }^{8}$ e Associação Brasileira de Pesquisadores(as) Negros(as) ${ }^{9}$, que formaram a Comissão Organizadora para um novo seminário que posteriormente daria origem a uma nova publicação. Da comissão fizeram parte também a Profa. Raquel de Oliveira e o Prof. Ivair Augusto Alves dos Santos, que estavam na organização do seminário de 1986. O seminário Raça Negra e Educação: 30 anos depois - E agora do que mais precisamos falar? ocorreu no campus da Unifesp, em São Paulo, nos dias 22, 23 e 24 de agosto de 2017.

Este artigo tem por objetivo apresentar e refletir sobre algumas das mudanças ocorridas no acesso de negros à educação brasileira, em especial para o período de 1991 a 2010, a partir dos Censos Demográficos do Instituto Brasileiro de Geografia e Estatística (IBGE) e apresentado como conferência na Mesa 1 - Desigualdades Raciais: avanços e persistências, no seminário de 2017.

\section{DESAFIO DE ATUALIZAR O RELATÓRIO DE 1986: OS DADOS QUANTITATIVOS SOBRE EDUCAÇÃO}

O relatório produzido pela FCC em 1986, como descrito, apresentava três módulos, sendo o terceiro a exposição dos dados produzidos a partir de tabulações especiais solicitadas ao Departamento de Indicadores Sociais (DEISO) do IBGE. Os dados eram originários do Censo Demográfico de 1980 e da Pesquisa Nacional por

\footnotetext{
${ }^{7}$ Participaram Sandra Unbehaum e Amélia Artes.

${ }^{8}$ Participaram Cleber Santos Vieira e João do Prado Ferraz de Carvalho.

${ }^{9}$ Participaram Anna Maria Canavarro Benite e Nicéa Quintino Amauro.
} 
Amostra de Domicílio (PNAD) de 1982, com foco na população residente no Estado de São Paulo ${ }^{10}$.

Uma advertência apresentada pelas autoras do relatório de 1986 deve ser reproduzida:

As interpretações que sugerimos no decurso desse capítulo devem ser consideradas apenas como ponto de partida para novas discussões. Tivemos, durante a realização desse trabalho, consciência da complexidade que envolve a comparação entre raças, de modo nem sempre claro e consciente, posturas contraditórias determinadas por envolvimentos afetivos e opções ideológicas ou políticas. (p. 203-204)

Este estudo (de 1986) pode ser considerado o primeiro a trabalhar com dados produzidos por demanda através de tabulações especiais feitas por técnicos do IBGE no recorte racial para a caracterização da situação educacional para um estado brasileiro. Anteriormente, os trabalhos localizados pelas autoras apresentavam e discutiam a única tabela publicada no censo de 1980 e que discorria sobre "pessoas de cinco anos ou mais, por cor e sexo, segundo a situação de domicílio e anos de estudo", cujos resultados foram utilizados nos estudos de Carneiro, De Oliveira Costa e Santos (1985), Rosemberg e Pinto (1985) e Beozzo (1983) (Rosemberg et al, 1984, p. 205).

Nesse sentido, a proposição de que era um estudo preliminar dava às autoras a segurança e tranquilidade em trabalhar com dados não antes produzidos ou analisados. Trazendo para os tempos atuais, o uso e disseminação de dados quantitativos em estudos na área da educação indicam uma mudança substancial nas possibilidades de análises e reflexões, a partir de levantamentos estatísticos produzidos por diferentes instituições de pesquisa.

\footnotetext{
${ }^{10}$ Este capítulo do relatório era organizado em cinco seções, a citar: 1) O preconceito das estatísticas Descrição dos processos de coleta e divulgação de estatísticas educacionais no recorte racial; 2) Indicadores Demográficos e Sociais - Apresentação de dados gerais e consolidados sobre a população negra residente no Estado de São Paulo; 3) Taxas de Alfabetização - Apresentação da evolução dos indicadores para negros através dos Censos; 4) Índices de Instrução - Taxas observadas para os negros na a interface com os rendimentos aferidos no mercado de Trabalho; 5) Informações gerais para os Estudantes - Descrição de taxas de escolarização para negros por faixa etária, sexo, renda familiar e informações sobre rendimento escolar, tipo de escola frequentada e impacto da escolarização na inserção no mercado de trabalho.
} 
Nas últimas décadas, a obtenção de informações quantitativas a partir de bases de dados consolidadas por instituições de pesquisa é muito mais acessível e ocorre, em muitos casos, a partir de plataformas de dados com interface virtual, de mais fácil manuseio. As principais instituições produtoras de informações numéricas que permitem a caracterização sociodemográfica da população brasileira no recorte educacional são o IBGE, em especial através dos censos demográficos, de periodicidade decenal, e as Pesquisas Nacionais por Amostra de Domicílio (PNADs), com periodicidade anual até 2014 e tornada contínua a partir de 2015.

Para dados educacionais, além das originárias do IBGE, outra fonte importante é disponibilizada pelo Inep ${ }^{11}$ (Instituto Nacional de Estudos e Pesquisas Educacionais Anísio Teixeira). Esse órgão, vinculado ao Ministério da Educação (MEC), é responsável pelo Censo da Educação Básica e pelo Censo do Ensino Superior, dentre outros levantamentos.

O avanço tecnológico na construção, gerenciamento e processamento de microdados observado na última década permitiu que informações quantitativas, antes de acesso mais restrito, pudessem ser acessadas e trabalhadas, o que permitiu uma infinidade de novas possibilidades de estudo a partir de diferentes demandas dos pesquisadores. Além do acesso às bases de microdados, ${ }^{12}$ que podem ser trabalhadas em software como o SPSS, ou SAS, o IBGE disponibiliza, em seu site, ferramentas (Sidra, $\mathrm{BME}^{13}$ ) que permitem o acesso a um grande conjunto de informações de forma direta e segura. Da mesma forma, no site do Inep, é possível localizar um amplo conjunto de

\footnotetext{
${ }^{11}$ O Inep foi criado em 1937, com o nome de Instituto Nacional de Pedagogia, e tinha dentre as suas incumbências "promover inquéritos e pesquisas" (FIBGE, 2013). A LDB de 1996 fortalece as funções do órgão, ao determinar em seu artigo $9^{\circ}$, inciso $\mathrm{V}$, que a "União incumbir-se-á de coletar, analisar e disseminar informações sobre a educação", cabendo ao Inep a responsabilidade por "organizar e manter o sistema de informações e estatísticas educacionais". Portaria ministerial de 1997 "tornou obrigatório o encaminhamento ao Inep, anualmente, de informações sobre a IES (Instituição de Ensino Superior), corpo docente e discente" (FIBGE, 2013). Desde 2008, a imputação de dados é realizada eletronicamente pelo sistema e-MEC (BRASIL - INEP, 2013). Apenas na década de 1990, os instrumentos do Inep passam a pesquisar o quesito cor em seus levantamentos estatísticos (Censos da Educação Básica e Superior) e nos exames e avaliações (Sistema de Avaliação da Educação Básica - Saeb; Exame Nacional do Ensino Médio - Enem; Exame Nacional de Desempenho dos Estudantes - Enade) (Senkevics; Machado; Oliveira, 2016).

${ }^{12}$ Os microdados representam a menor fração de uma informação coletada (indivíduo, escola) e estão relacionados a uma pesquisa ou sistema de avaliação. A partir da agregação de microdados é possível construir uma determinada análise quantitativa.

${ }^{13}$ SIDRA: Sistema IBGE de recuperação automática BME: Banco Multidimensional de Estatísticas IBGE
} 
informações já processadas (Data Escola Brasil, Inep Data, Painel Educacional, entre $\left.\operatorname{outros}^{14}\right)$.

Nas últimas décadas, além das publicações do IBGE e Inep, foram produzidos estudos com a apresentação de informações educacionais quantitativas no recorte de cor/raça por instituições como o Instituto de Pesquisa Econômica Aplicada (Ipea) (2014, 2011), que, além de documentos específicos publicizados em seus "Textos de Discussão", produziram dois artigos que se tornaram referências na literatura: Henriques (2001) e Beltrão e Teixeira (2004).

Outro material de referência são as publicações do Laboratório de Análises Econômicas, Históricas, Sociais e Estatísticas das Relações Raciais (LAESER): os “Relatórios Anuais de Desigualdades Raciais no Brasil" (2008 e 2010), organizadas por Marcelo Paixão. Em sua última publicação, a partir de dados da PNAD, apresenta informações sobre as assimetrias por cor/raça e por sexo em diferentes aspectos sociais: saúde, assistência social, vitimização, previdência social e acesso aos sistemas de ensino.

O Grupo de Estudos Multidisciplinar da Ação Afirmativa (GEMAA), criado em 2008 e sediado no Instituto de Estudos Sociais e Políticos da Universidade do Estado do Rio de Janeiro IESP-UERJ, é um grupo de pesquisa dedicado ao estudo das políticas de Ação Afirmativa, com uma grande produção de estudos e textos de discussão que podem ser acessados pelo site da instituição. ${ }^{15}$

Outras instituições devem ser lembradas, como a Fundação Sistema Estadual de Análise de Dados (Seade), que produz estudos que descrevem o mercado de trabalho por grupos raciais e apresentam informações na interface educação para o estado de São Paulo; o Conselho de Desenvolvimento Econômico e Social (CDES), dentre outras instituições, além de um conjunto cada vez maior de plataformas on-line que disponibilizam informações no recorte racial, a citar: Movimento Todos pela Educação,

\footnotetext{
${ }^{14}$ Disponível em: www.inep.gov.br

${ }^{15}$ Disponível em: http://gemaa.iesp.uerj.br/. Acesso em25/10/2017
} 
em sua plataforma de acompanhamento das metas do Plano Nacional de Educação ${ }^{16}$; o Observatório da População Negra, uma parceria da Universidade Zumbi dos Palmares e Secretaria de Assuntos Estratégicos e Especial de Promoção da Igualdade Racial, criada em 2012 e que centraliza o primeiro banco de dados nacional sobre a população negra. O intuito dessa pequena descrição não é o de esgotar as instituições que têm, nos últimos tempos, publicizado estudos quantitativos no recorte racial, pois só essa demanda geraria um estudo específico e próprio, mas ressaltar as mudanças nas possibilidades de trabalho com dados disponibilizados em pesquisas de caracterização populacional, em especial da população negra. Um quadro bem diferente do apresentado no relatório de 1986.

Um cuidado importante e ressaltado na literatura (Rosemberg; Artes, 2012; Souza, 2013) é que conjuntos de dados disponibilizados por diferentes instituições de pesquisa não devem ser comparados diretamente por trabalharem com definições e conceitos distintos de unidades de coleta, desenho amostral ou formação de cadastro de informações, procedimentos de processamento. Dessa forma, devem servir cada qual na sua especificidade, para a construção de um quadro descritivo da realidade que se pretende estudar.

Nesse sentido, há maior acessibilidade no trato de dados oficiais e estatísticos de maneira que pesquisadores autonomamente conseguem processar e produzir seus próprios dados, a partir de seus problemas de pesquisa específicos. Além disso, outras instituições de pesquisa também atuam na produção de dados e colaboraram com pesquisas em andamento ao colocar novas agendas de pesquisa sem ter que aguardar pelo processamento dos órgãos oficiais, criando um relacionamento profícuo de interação e complementariedade entre as instituições.

\section{BREVE REFLEXÃO DA CONSTRUÇÃO DA VARIÁVEL RAÇA/COR NAS ESTATÍSTICAS BRASILEIRAS}

\footnotetext{
16 Disponível em: http://www.todospelaeducacao.org.br/educacao-na-midia/indice/40499/educacaoreforca-desigualdades-entre-brancos-e-negros-diz-estudo-do-todos-pela-educacaol. $\quad$ Acesso em025/10/2017
} 
Das seções descritas no relatório de 1986 é importante nos atermos à primeira, que trata do preconceito das estatísticas. Segundo as autoras, a classificação racial no Brasil, ao contrário de outros países, em especial os EUA, ocorre pela avaliação da cor da pele e não por questões de ancestralidade:

Esta diferenciação entre pretos e pardos tem sido questionada por estudiosos e militantes do movimento negro, na medida em que cinde o contingente de pessoas de origem étnica africana. Classificar as pessoas pela cor, e não pela raça, separando pretos e pardos, significaria, de certa forma, subdividir uma população que, na verdade, apresenta trajetórias e destinos sociais bastante semelhantes. (Rosemberg et al.1986, p. 201)

Para as autoras do relatório, "silencia-se sobre o tema como estratégia de negação da existência de diferenças raciais" (1986, p. 202).

Esses temas são retomados por Silva e Hasenbalg (2000), Nogueira (2007), e Senkevics, Machado e Oliveira (2016).

Os estudos de Carlos Hasenbalg e Nelson do Valle e Silva, nos anos de 1980/1990, são marcos nas discussões sobre desigualdades por cor/raça na população brasileira. Esses autores, de forma pioneira, utilizando-se das bases de dados nacionais (IBGE) disponíveis à época, no recorte cor/raça, indicaram que as desigualdades educacionais observadas entre brancos e negros não se limitavam exclusivamente a questões socioeconômicas. Os autores afirmavam ser necessário o ingresso da dimensão racial para a discussão das estruturas de classes ou estratificação social. Em outras palavras, as desigualdades brasileiras precisam ser avaliadas levando em consideração o racismo que perdura na estrutura social e histórica brasileira. De forma concomitante, o Movimento Negro organizado passou a propagar em seus espaços de discussão e luta a necessidade da garantia de acesso, permanência e qualidade na educação para os negros, em todas as etapas de escolarização, incluindo o ensino superior.

Segundo Nogueira (2007), os primeiros estudos na perspectiva sociológica a diferenciarem brancos e não brancos datam da década de 1930/1940 realizados por Donald Pierson, na Bahia, e na década de 1950, por Roger Bastide, em São Paulo, seguido de estudos em diferentes regiões do país. Parte das pesquisas foram financiadas pela Unesco (Organização das Nações Unidas para a Educação, a Ciência e a Cultura) e indicavam a existência de preconceito racial no Brasil: 
Assim, pela primeira vez o depoimento dos cientistas sociais vem, francamente, ao encontro e em reforço ao que, com base em sua própria experiência, já proclamavam, de um modo geral, os brasileiros de cor (2007, p. 291).

Nogueira diferencia o preconceito de marca, baseado no fenótipo, ou a aparência racial, e que caracteriza as relações raciais no Brasil de forma diversa do modelo norteamericano, preconceito de origem: "o negro é definido oficialmente como todo o indivíduo que, em sua comunidade, é conhecido como tal, sem qualquer referência a traços físicos" (2007, p. 294), que é, portanto, marcado pela descendência da pessoa, independente da sua cor de pele.

Nos anos de 2000, Paixão (2012) ressalta a questão da visibilidade dos negros em diferentes espaços sociais e também nas estatísticas públicas produzidas. Para o autor, o quesito cor/raça é apresentado em diferentes fontes de dados estatísticos, apresentando problemas como os de terminologia ou a subnotificação de dados; em outro aspecto, a maior visibilidade estatística dos negros é resultado das lutas empreendidas pelo movimento negro desde os anos 1980:

\begin{abstract}
Desta maneira, os avanços observados, tanto em termos da ampliação da quantidade de bases de dados estatísticos no Brasil, que contém a variável cor ou raça, como o paulatino aumento do percentual dos que se declararam ou pardos, ou pretos - especialmente no Censo Demográfico e na PNAD -; reflete que de alguma forma, talvez, a luta pela visibilidade estatística tenha sido uma das frentes de luta mais bem-sucedida por parte do movimento negro brasileiro contemporâneo nos últimos anos. (Paixão, 2012, p. 27).
\end{abstract}

Enquanto nos dados disponibilizados pelo Inep o quesito cor/raça adentra nos anos de 1990, a leitura dos censos demográficos e pesquisas amostrais do IBGE indicam diferentes inserções ou ausências, como uma construção histórica e social para o quesito racial nas pesquisas realizadas (Oliveira, 2001). O primeiro censo demográfico, datado de 1872, tinha por objetivo conhecer a população brasileira para implantação de políticas públicas, no trato eleitoral e no reconhecimento das características da nação, para tanto tinha quesitos sobre: sexo, cor, idade, estado civil, residência, grau de instrução, religião, naturalidade, nacionalidade, religião e enfermidades aparentes. Para o quesito cor, as opções de resposta incluíam: branca, preta, parda e cabocla. A população brasileira era predominantemente negra (na junção de pretos e pardos totalizavam 58\%). Piza e Rosemberg (1999) já indicavam que a 
primeira contagem populacional apresentava um misto de cor (branca, preta e parda) e raça (cabocla), marcas fenotípicas e de descendência. A mesma estrutura para a medição da cor/raça da população brasileira foi utilizada em 1890, primeiro censo realizado na nascente República, com a substituição de pardo por mestiço.

O quesito cor/raça só retorna no Censo de 1940, lembrando que, nos 50 anos de intervalo, o país passou por mudanças econômicas, processo de urbanização e industrialização e pelas correntes sociológicas do racismo científico, que apresentavam os negros em uma categoria de inferioridade, associada ao incentivo da imigração europeia e asiática e às políticas de branqueamento (Petruccelli, 2012). Nesse Censo, organizado pelo IBGE, instituição recém-criada, as opções de resposta eram: branco, preto, pardo e amarelo (para dar dimensão da imigração asiática).

Essa apresentação dos quesitos é mantida até o Censo de 1960, sendo que o realizado em 1970, período de ditadura civil militar, o quesito racial desapareceu. Segundo Piza e Rosemberg (1999), não foi dada pelo IBGE justificativa para tal ausência. A pergunta volta no Censo de 1980, por pressão do Movimento Negro, que demandava por informações de caracterização do seu grupo populacional.

A última mudança ocorreu no Censo de 1991, com o retorno da opção indígena, permanecendo constante até o realizado em 2010: brancos, pretos, amarelos, pardos e indígenas.

Vale ressaltar que as PNADs, com uma periodicidade menor que os censos, foram introduzidas no final dos anos de 1960, baseadas no modelo norte-americano e com o objetivo de produzir um sistema integrado e contínuo de pesquisas domiciliares, para produção de dados de interesse nacional e que permitissem uma comparabilidade internacional. O quesito cor/raça foi tema de um suplemento especial na pesquisa realizada em 1976 e que tinha por objetivo dimensionar os problemas da identidade e da identificação racial do povo brasileiro. Comparou-se a resposta para dois quesitos, o primeiro de resposta espontânea diante da indagação "Qual a cor do Sr (Sra)?; e o segundo com as categorias pré-definidas: branca, preta, amarela e parda. Os resultados estão apresentados na Figura 1.

Figura 1. Respostas para o quesito cor (Pesquisa PNAD 1976) 


\begin{tabular}{|c|c|c|c|c|c|c|c|c|c|}
\hline \multirow{2}{*}{$\begin{array}{c}\text { Cor } \\
\text { induzida }\end{array}$} & \multicolumn{9}{|c|}{ Cor espontânea } \\
\hline & Branca & Preta & Parda & Amarela & Morena & Morena-clara & Clara & Outras & Total \\
\hline Branca & 42,8 & 0,1 & 0,2 & 0,1 & 8,2 & 1,5 & 2,0 & 2,3 & 57,2 \\
\hline Preta & 0,1 & 4,2 & 0,2 & 0,0 & 3,0 & 0,1 & 0,0 & 1,0 & 8,5 \\
\hline Amarela & 0,4 & 0,0 & 0,1 & 0,8 & 0,9 & 0,2 & 0,1 & 0,3 & 2,7 \\
\hline Parda & 0,8 & 0,4 & 6,7 & 0,1 & 21,0 & 0,9 & 0,2 & 1,5 & 31,6 \\
\hline Total & 44,0 & 4,7 & 7,1 & 1,0 & 33,0 & 2,7 & 2,3 & 5,1 & 100,0 \\
\hline
\end{tabular}

Fonte: Osorio (2003, p. 25) (Tabela 4 - Cor induzida versus cor espontânea (BRASIL, 1976 - IBGE, PNAD, 1976. Elaboração Disoc/Ipea).

Osorio (2003) apresenta uma profícua discussão sobre o sistema classificatório de cor/raça do IBGE, na interface com outras pesquisas que procuraram identificar a riqueza de autoclassificação racial do brasileiro. Conforme o resultado encontrado para a PNAD 1976, apesar dos 136 termos encontrados para a declaração livre, em 57\% dos casos as opções coincidiam com as ofertadas pelo IBGE, e 38\% das respostas eram referentes aos termos: morena, morena clara e clara. Dessa forma, para 95\% das respostas, sete termos davam conta da autoclassificação livre da população brasileira, indicando que, mesmo com as críticas desenhadas, as opções de resposta ofertadas pelo IBGE são de conhecimento e uso no processo de autoidentificação da população.

\section{RETRATO DA EDUCAÇÃO EM 1986 E AS MUDANÇAS NA ATUALIDADE: NOVOS DE PARADIGMA}

Este texto não tem por objetivo atualizar todas as informações quantitativas, construídas com tantas limitações, no relatório de 1986 (o relatório possui 79 tabelas e gráficos). Essa é uma demanda que constitui um projeto de pesquisa a ser desenvolvido futuramente. O objetivo é apresentar informações dos três últimos censos (1991, 2000 e 2010), indicando que o quadro de acesso dos negros à educação foi substancialmente alterado. Ao contrário do relatório de 1986, que focava na realidade educacional para o estado de São Paulo, este estudo apresenta um panorama nacional.

A leitura do relatório deixa premente que os gargalos ou dificuldades para os negros acessarem as etapas da educação concentravam-se nas séries iniciais na educação básica. Esse quadro, considerando os 30 anos passados, foi alterado substancialmente e as "bandeiras" hoje postas pelo Movimento Negro envolvem o acesso às etapas mais elevadas da escolarização, como o ensino superior e os cursos de pós-graduação. As informações apresentadas em 1986 trabalhavam com taxas de 
alfabetização, de escolarização e de instrução. O acesso ao $3^{\text {a }}$ grau (nomenclatura utilizada no texto para referir-se ao ensino superior) é apresentada em apenas oito tabelas, associando a questão da maior renda para pessoas com níveis de escolarização mais elevadas.

Apenas para ilustração, serão apresentadas a seguir três informações descritas no relatório (figuras 2, 3 e 4), desagregadas para os grupos de brancos e negros para a população do estado de São Paulo. Segundo o relatório, a presença de negros na população paulista era de $44,7 \%$ - um índice importante para a compreensão dos dados apresentados adiante.

Um diferencial importante do relatório é que algumas informações foram desagregadas por grupos de sexo e cor/raça, constituindo quatro grupos de análise: mulheres brancas, mulheres negras, homens brancos e homens negros. Esse intercruzamento de marcadores sociais da diferença (sexo, cor/raça, classe, entre outros) é conhecido nos estudos de gênero e em algumas correntes da teoria feminista como interseccionalidade $^{17}$, tendo como autores de referência Crenshaw (2002), Mcclintock (1995), Piscitelli (2008). No Brasil, Fúlvia Rosemberg se utiliza dessa desagregação, tanto no relatório de 1986 como em textos posteriores ao relatório (Rosemberg, 2001; Rosemberg; Madsen, 2011).

As três tabelas apresentadas permitem a construção de um panorama dos indicadores educacionais de década de 1980 pelo recorte racial.

Figura 2. Taxa de escolarização - 1986

\begin{tabular}{|l|c|c|c|}
\hline Grupos de idade & Brancos & Negros & $\begin{array}{c}\text { Outros/Sem } \\
\text { declaração }\end{array}$ \\
\hline 7 a 9 anos & 84,9 & 74,8 & 92,7 \\
\hline 10 a 14 anos & 84,3 & 77,8 & 93,6 \\
\hline 15 a 17 anos & 56,9 & 40,8 & 83,0 \\
\hline 18 e 19 anos & 36,2 & 20,6 & 64,4 \\
\hline 20 a 24 anos & 19,6 & 9,3 & 41,7 \\
\hline Total & $\mathbf{5 5 , 9}$ & $\mathbf{4 5 , 8}$ & $\mathbf{7 3 , 1}$ \\
\hline
\end{tabular}

\footnotetext{
${ }^{17}$ Outra linha teórica do feminismo marxista francólogo trabalha com os conceito de consubstancialidade (ver Hirata, 2014; Kergoat, 2010).
} 
Fonte: Relatório FCC, p. 325 (tabela 5.5 - Taxa de escolarização segundo a cor e o grupo de idade - São Paulo - 1980. Tabulação especial do Censo Demográfico 1980).

A Figura 2 indica a taxa de escolarização, entendida como a proporcionalidade entre as pessoas que frequentam a escola e o total da população para cada faixa etária. Na comparação entre brancos e negros, as marcas da desigualdade estão presentes em todas as faixas etárias e tendem a ampliar com o aumento da faixa etária. Na faixa etária dos 20 aos 24 anos, que representa, em tese, a frequência ao ensino superior, os índices para os brancos são o dobro dos encontrados para os negros. Mesmo o acesso inicial (7 a 9 anos) tem uma forte diferenciação racial, com mais de 10 pontos percentuais de diferença.

Figura 3. Distribuição de estudantes - 1986

\begin{tabular}{|c|c|c|c|c|}
\hline \multirow{2}{*}{ Séries } & \multicolumn{2}{|c|}{ Brancos } & \multicolumn{2}{c|}{ Negros } \\
\cline { 2 - 5 } & 1940 & 1982 & 1940 & 1982 \\
\hline \multirow{2}{*}{ Até a 4 $^{\text {a }}{\text { série do } 1^{\text {o }} \text { grau (ou grau elementar) }}^{*} 81,2$} & 45,9 & 93,4 & 64,2 \\
\hline Além da 4 $^{\text {a }}$ série do $1^{\text {o }}$ grau & 18,8 & 54,1 & 7,6 & 35,8 \\
\hline Total & $\mathbf{1 0 0}$ & $\mathbf{1 0 0}$ & $\mathbf{1 0 0}$ & $\mathbf{1 0 0}$ \\
\hline
\end{tabular}

Fonte: Relatório FCC, p. 342- (Tabela 5.12 - Distribuição dos estudantes por série de ensino segundo cor - 1940 e 1982. Nota: o Censo de 1940 coletou informações sobre estudantes entre 5 e 39 anos, enquanto o de 1982, na faixa de 7 a 24 anos.)

Outro caminho de análise é considerar as etapas (ou anos escolares) frequentadas pelos grupos. A Figura 3 descreve dados de 1940 (Censo Demográfico) e 1982 (PNAD). Nos anos de 1940, a quase totalidade da população concentrava-se na primeira etapa de escolarização (na atualidade refere-se ao final do nível fundamental 1), apenas 7,6\% dos negros (na faixa etária de 5 a 39 anos) tinham ultrapassado a $4^{\mathrm{a}}$ série, índice que chegava a 18,8\% para os brancos. Para 1982, os indicadores são bem melhores, em especial para os brancos: quase metade $(45,9 \%)$ ultrapassou a $4^{\mathrm{a}}$ série, enquanto para os negros a relação é de dois negros que passaram da $4^{\mathrm{a}}$ série para cada um negro que ainda está na fase inicial da escolarização. Essa "fotografia" demonstra uma marca intensa de desigualdade entre os grupos por cor/raça e que, para os negros, os limites de escolarização eram muito iniciais.

Figura 4. Atraso escolar - 1986

\begin{tabular}{|l|l|}
\hline Grupo de idade & Em porcentagem \\
\hline
\end{tabular}




\begin{tabular}{|c|c|c|c|c|c|c|c|c|c|c|}
\hline & \multicolumn{3}{|c|}{ Sem atraso } & \multicolumn{3}{c|}{ Até 2 séries } & \multicolumn{3}{c|}{ Mais de 2 séries } & \multirow{2}{*}{ Total } \\
\cline { 2 - 10 } & B & N & T & B & N & T & B & N & T & \\
\hline 7 a 9 anos & 67,6 & 50,0 & 63,8 & 32,4 & 50,0 & 36,2 & & & & 100,0 \\
\hline 10 a 14 anos & 35,4 & 14,4 & 30,9 & 45,6 & 48,6 & 43,0 & 19,6 & 37,0 & 23,1 & 100,0 \\
\hline 15 a 17 anos & 27,6 & 8,1 & 24,6 & 38,8 & 30,4 & 37,2 & 33,4 & 62,0 & 38,2 & 100,0 \\
\hline
\end{tabular}

Fonte: Relatório FCC, p. 352 (Tabela 5.15 - Atraso escolar de estudantes entre 7 e 17 anos, de acordo com a cor e segundo a idade São Paulo, 1980. Tabulação especial)

Os indicadores de atraso escolar finalizam o quadro apresentado (Figura 4) e reforçam os diferenciais de escolaridade por grupos raciais. Os recortes de idade descritos podem ser considerados como os esperados para a frequência ao fundamental 1 (7 a 9 anos), fundamental 2 (10 a 14 anos) e ensino médio (15 a 17 anos). Apenas $8,1 \%$ dos negros estão na idade correta no ensino médio (sem atraso), 1/3 do valor encontrado para os brancos. Enquanto $62 \%$ dos jovens negros apresentam mais de dois anos de atraso em seus processos de escolarização, essa taxa é de 33,4\% para os brancos. Diferença semelhante é observada para os mais novos: apenas metade dos negros está sem atraso na faixa de 7 a 9 anos, e 14,4 para a idade de 10 a 14 anos.

As informações apresentadas acima, apesar de terem por origem indicadores diferentes - taxa de escolarização, distribuição de estudantes por ano escolar e atraso escolar -, caminham na mesma direção: as marcas das desigualdades a partir dos recortes por cor/raça são intensas e indiscutíveis. Se os resultados educacionais são ruins para todos, os negros apresentam os menores valores de acesso aos bens educacionais ofertados à época. Vale lembrar que o relatório trabalha com valores para o estado de São Paulo. Fica a reflexão: se tal era a realidade para o estado mais rico do país, como seria a situação educacional dos negros nas regiões Norte e Nordeste, em que são maioria populacional?

\section{ATUALIZAÇÃO DA PESQUISA: ESCOLHAS FEITAS}

Após a leitura do relatório de 1986 e a partir do conhecimento advindo das leituras realizadas sobre o tema da escolarização de negros no Brasil, é consenso que muito se alterou no desenho descrito. Assim, por escolha metodológica, conceitual e teórica decidiu-se apresentar dados referentes às etapas mais elevadas da escolarização, em especial o ensino médio e superior e no recorte Brasil, não apenas de um estado. Os 
dados foram coletados no Banco Multidimensional de Estatísticas (BME) ${ }^{18}$, uma ferramenta on-line de busca, recuperação e manuseio das informações disponibilizadas para as pesquisas realizadas pelo IBGE. É uma plataforma "amigável”, que permite cruzamentos de variáveis e recortes temporais e por desagregações regionais sem a necessidade de uso de pacotes estatísticos ou o manuseio de microdados.

Como o quesito racial é central no estudo, trabalhou-se com as informações dos Censos de 1991 até 2010, que apresentam as mesmas opções de resposta para a pergunta: a sua cor ou raça é? (branca, preta, amarela, parda e indígena). Os resultados discutem aspectos referentes a: mudança da configuração racial do país por região geográfica; etapa de escolarização mais elevada concluída; etapa de escolarização frequentada e interface condição de trabalhador e estudante.

Inicialmente é apresentada uma discussão sobre a mudança na configuração racial da população brasileira no período de 1991 a 2010 e os diferenciais regionais para, na sequência, apresentar os indicadores de escolarização escolhidos. Para este segundo conjunto de dados, os resultados estão desagregados para os grupos de sexo e cor/raça, constituindo-se quatro grupos: homem branco, mulher branca, homem negro e mulher negra.

\section{O BRASIL MUDOU DE COR?}

O Gráfico 1 apresenta a distribuição por cor da população brasileira para os três censos demográficos. Em especial na década de 2000 a 2010, a presença de pretos e pardos se amplia, invertendo a pertença racial do povo brasileiro, que passa de branca para predominantemente negra.

Gráfico 1. Distribuição por cor/raça da população brasileira - Brasil

${ }^{18}$ Disponível em: https://www.bme.ibge.gov.br. Acesso em: 22/11/2017 


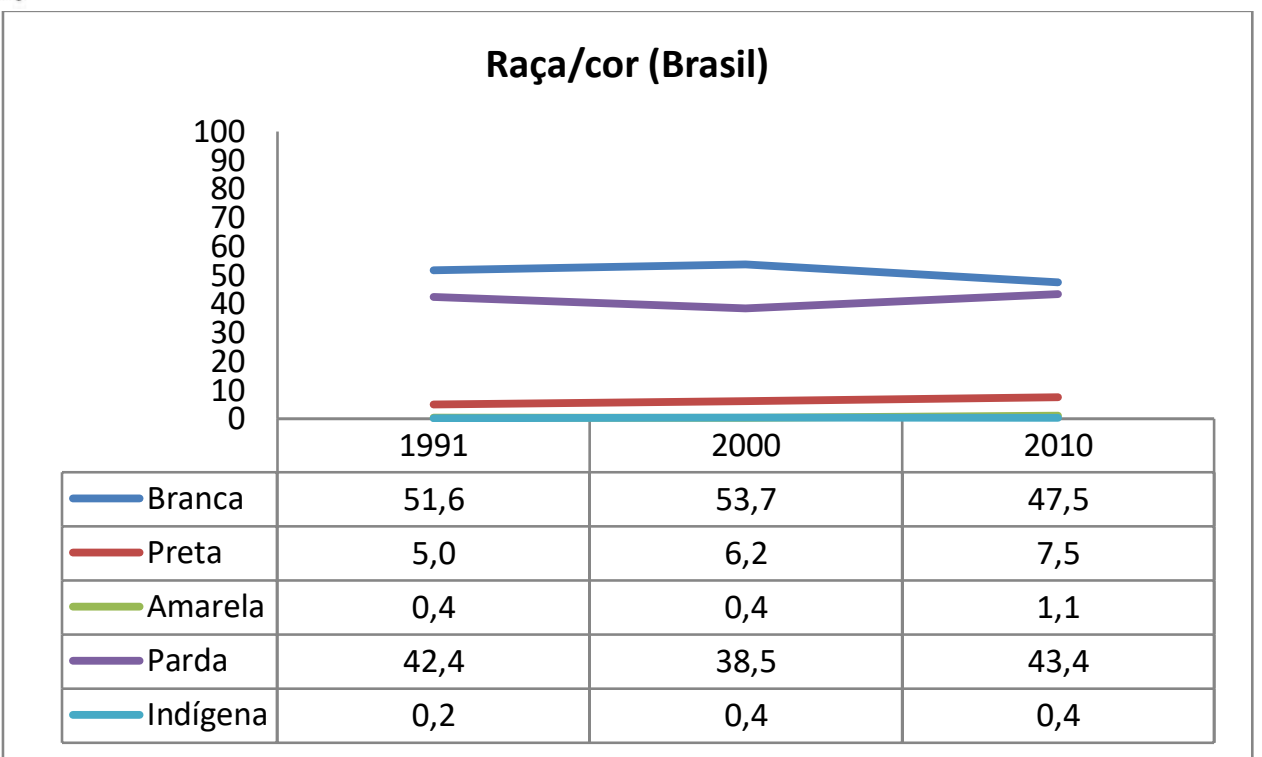

Fonte: Organizado pelas autoras com base nos dados do IBGE, BME, Censo Demográfico 1991, 2000 e 2010 .

A diminuição dos que se autodeclararam brancos na população geral entre os censos de 2000 e 2010 é compensada pela ampliação dos que se declararam pretos e pardos, com um índice pouco maior para pretos (variação de 36,0\%) do que para pardos (variação de 26,8\%). Em 2000, os pretos e pardos representavam 44,7\% e em 2010, $50,9 \%$ do universo. Essa alteração já foi detectada por outros autores a partir de resultados das PNADs, realizadas na última década. Segundo Cunha (2012):

Este fenômeno pode ser atribuído tanto a um diferencial de fecundidade - a taxa de fecundidade global das mulheres negras é de 2,1 e das brancas 1,6 filhos por mulher, no nível de reposição dos dois grupos -, e/ou pelo aumento sistemático de população que se autodeclara negra devido a um processo de conscientização da importância de assumir sua própria identidade (p. 3).

Sergei Soares (2008) segue a mesma reflexão ao discutir a mudança na autoclassificação racial da população brasileira na última década, que não se justificaria apenas pelas alterações nas taxas de fecundidade, mas que encontraria explicação, principalmente, na alteração da autoclassificação da população de brasileiros:

Pode-se dizer que o que está acontecendo não é que o Brasil esteja tornando-se uma nação de negros, mas, sim, que esta se assumindo como tal (Soares, 2008, p. 116).

Assim, fica uma questão em aberto para novos estudos e que envolve: a melhoria observada nos indicadores educacionais para os negros é resultado direto de 
uma ampliação de acesso educacional para esse universo ou é produto da alteração no processo classificatório de cor/raça das pessoas?

Como a distribuição racial por região é bastante díspare, os gráficos 2 a , b, c, d e e apresentam as distribuições raciais para as cinco regiões geográficas. Enquanto nas regiões Norte e Nordeste a participação de negros está acima de $70 \%$ nos três censos, chama a atenção a ampliação dos autodeclarados pretos, com um aumento representativo entre 1991 e 2010. Em outro extremo, as regiões Sudeste e em especial a Sul apresentam um predomínio de brancos.

Considerando que distribuição de oferta escolar é diferenciada por região geográfica com melhores indicadores de acesso, oferta e desempenho concentradas na região Sudeste (Sampaio, 2017; Suliano; Siqueira, 2012), fica a reflexão: os indicadores de escolarização para os negros são piores na comparação com os brancos por fatores como trajetórias escolares diferenciadas, racismo institucional que atua nos espaços escolares ou deve-se, também, a uma menor oferta de escolaridade nas regiões geográficas em que os negros predominam, assim como a maior presença nas zonas rurais? A hipótese é que os diferenciais encontrados nos indicadores educacionais são resultado de uma confluência de fatores: tanto internos ao espaço escolar, como macroestruturais, assim como resultado da menor oferta de ensino em algumas regiões do país.

Gráfico 2. a, b, c, d e Distribuição por cor/raça e região demográfica - Brasil

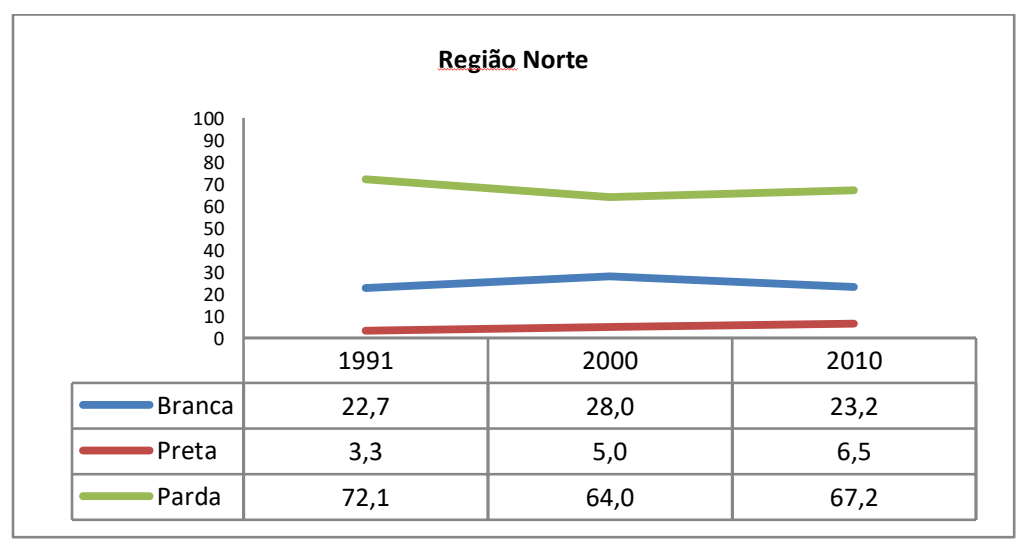



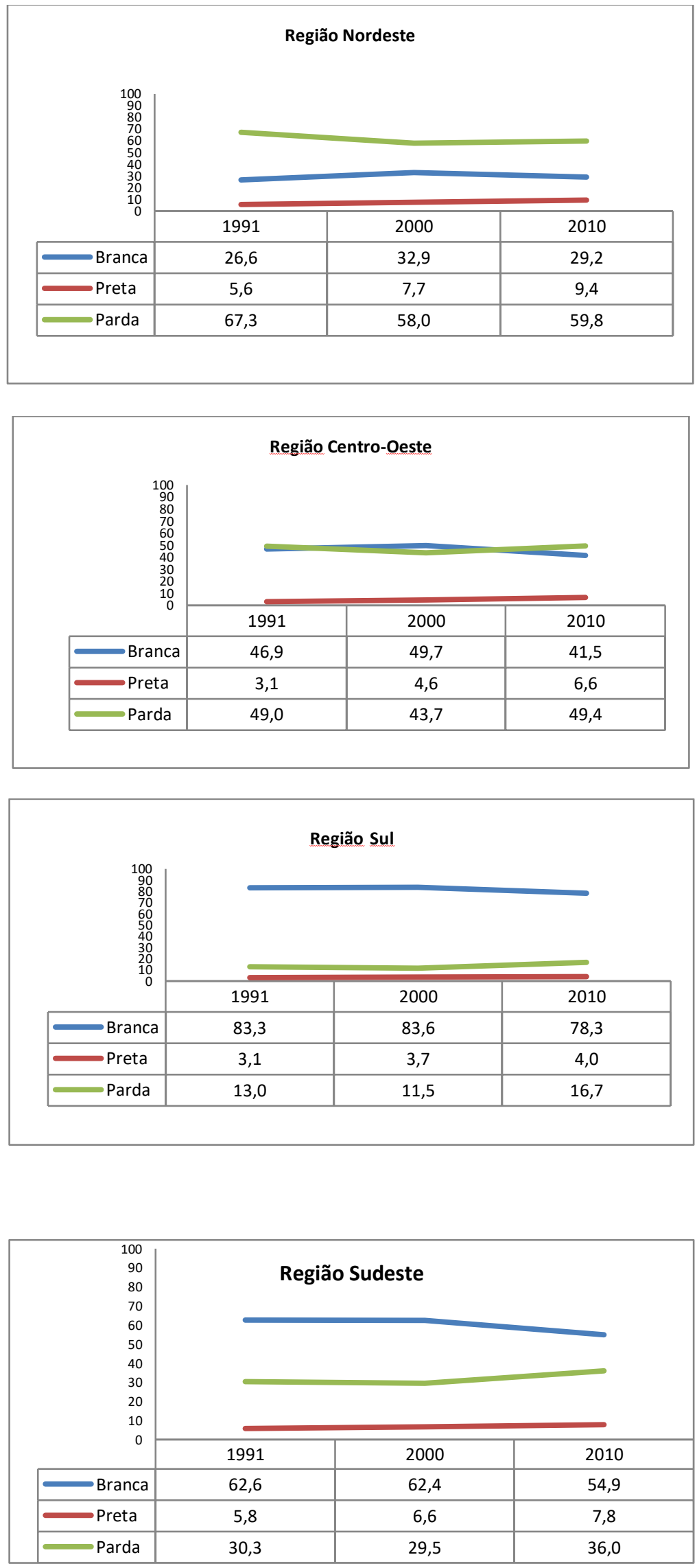


\section{APRESENTAÇÃO DOS RESULTADOS PARA OS CENSOS DE 1991 A 2010}

Os dados apresentados neste estudo concentram-se em três dimensões: etapa mais elevada concluída (para os que não frequentam a escola); frequência à escola e associação entre a condição de estudantes e o ingresso no mercado de trabalho para as etapas do ensino médio e superior.

A escolha pela última etapa da educação básica e o acesso ao ensino superior está em concordância com a literatura atual que indica que os processos de universalização que marcaram as políticas educacionais nas décadas de 1980 e 1990, resultados da determinação na normativa de obrigatoriedade do acesso e permanência na escola dispostos na Constituição Federal de 1988 e a Lei de Diretrizes e Bases da Educação (LDB lei n. 9394/96), ampliaram a cobertura no ensino fundamental, com indicadores próximos de 100\% de cobertura (Lima, 2011; Oliveira, 2007; Franco; Alves; Bonamino, 2007).

A apresentação separada das informações por etapa (ensino médio e ensino superior) explicitam as diferenças no acesso distinto para homens e mulheres, negros e brancos. Para o ensino médio, as marcas maiores estão na variável sexo; enquanto, para o ensino superior, as desigualdades trazem, de forma mais intensa, as marcas da cor/raça. Trabalha-se com a interseccionalidade sexo e cor/raça, na formação de quatro grupos: homem branco e mulher branca e homem negro e mulher negra. Os resultados indicam uma hierarquia, estando as mulheres brancas com os melhores indicadores e os homens negros com os piores.

Antes da apresentação dos dados, faz-se necessário um esclarecimento para a leitura correta das tabelas. Trabalha-se com uma "desejada" paridade entre os grupos. Isto é, considera-se de forma "simplificada" que a população brasileira é formada por $50 \%$ de homens e $50 \%$ de mulheres ${ }^{19}$ e $50 \%$ de negros e $50 \%$ de brancos $^{20}$, dessa forma, cada grupo de sexo e cor/raça teria $25 \%$ de participação. Os valores acima e abaixo dos

\footnotetext{
${ }^{19}$ Dados do Censo Demográfico 2010 indicam 49\% de homens e 51\% de mulheres.

${ }^{20}$ Dados do Censo Demográfico 2010 indicam 47,5\% de brancos e 50,9\% de negros.
} 
$25 \%$ indicam as desigualdades observadas para os indicadores educacionais selecionados.

\section{ENSINO MÉDIO}

Uma variável ofertada pelos censos é a etapa de escolarização mais elevada (concluída com aprovação) da população. Isso nos permite construir uma fotografia do perfil educacional da população que não frequenta mais a escola.

O Gráfico 3 apresenta os resultados para os que finalizaram a educação básica (o ensino médio) e que não completaram o ensino superior. Os últimos 30 anos permitiram o equilíbrio entre os grupos, com uma aproximação em 2010 dos 25\% "esperados", resultado dos processos de universalização do ensino fundamental e consequentemente do acesso ao ensino médio. As mulheres brancas e negras apresentam as maiores taxas, enquanto os homens negros exibem os piores valores $(23,2 \%)$.

Uma informação importante para a compreensão dos dados é a taxa de crescimento de acesso ao ensino médio para o período: em 1991, um total de 11.117.793 de pessoas haviam concluído o $2^{\circ}$ grau (nomenclatura usada na época); já em 2010, esse número é de 36.758.008, indicando uma taxa de variação de 230,6\%.

\section{Gráfico 3. Etapa mais elevada concluída, Ensino Médio por sexo e cor/raça. Brasil}

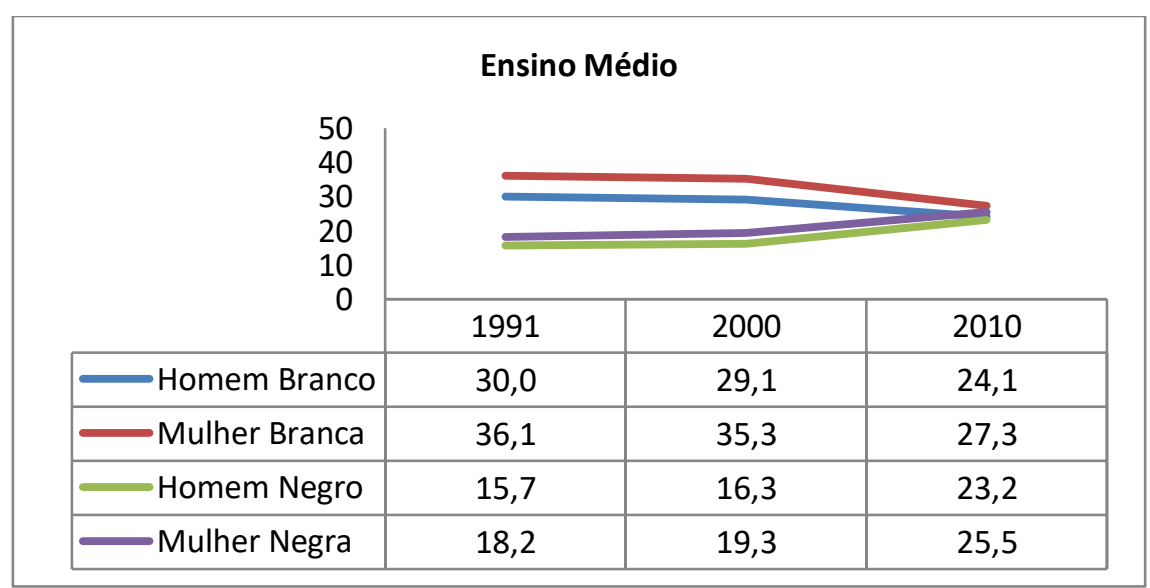

Fonte: Organizado pelas autoras com base nos dados do IBGE, BME, Censo Demográfico 1991, 2000 e 2010.

Um retrato mais próximo dos processos de escolarização pode ser verificado no

Gráfico 4, que apresenta os resultados para o universo de pessoas que frequenta a escola 
(Ensino Médio). O crescimento para as mulheres negras e para os homens negros é constante desde 1991, aproximando-se dos 25\% esperados (a partir da representação populacional). Vale refletir sobre o valor observado para as mulheres negras: 28,8\%, indicando uma maior presença nessa etapa de escolarização. Entender tal situação demanda uma reflexão específica sobre o histórico e características dessa modalidade de escolarização e que sai do escopodo trabalho proposto. A taxa de variação entre 1991 e 2010 é de $170,6 \%$ para o universo pesquisado, chegando a 334,7\% para os homens negros e 264,4\% para as mulheres negras, indicando que esses grupos passaram a alcançar essa etapa de escolarização.

\section{Gráfico 4. Pessoas que frequentam a escola, Ensino Médio por sexo e cor/raça. Brasil}

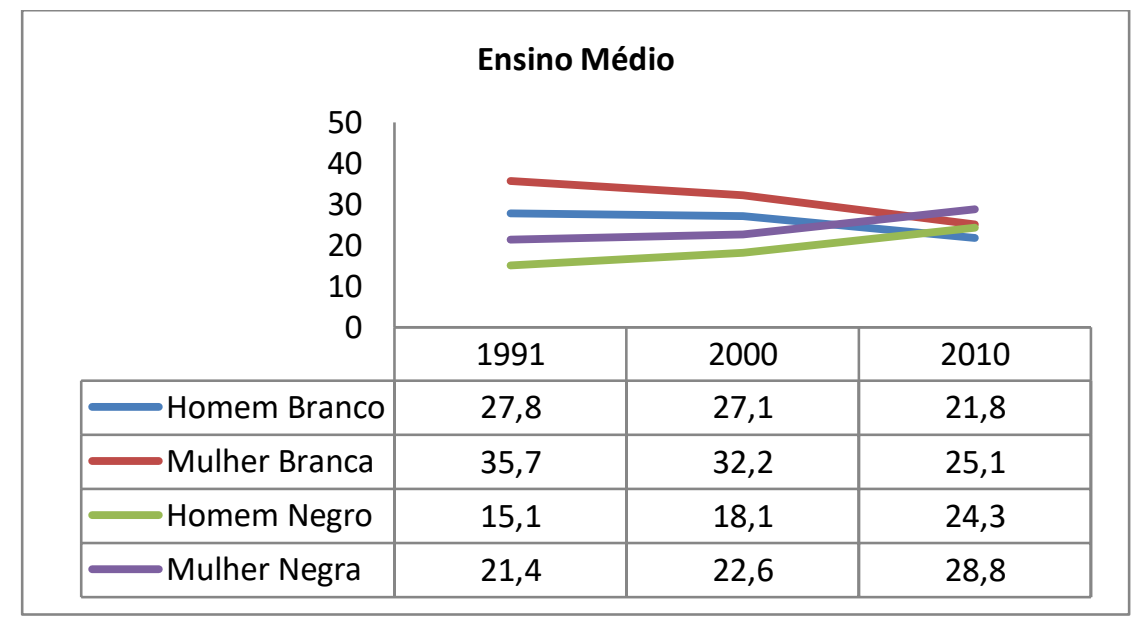

Fonte: Organizado pelas autoras com base nos dados do IBGE, BME, Censo Demográfico 1991, 2000 e 2010.

Os resultados descritos para o ensino médio merecem uma atenção maior, e para tanto será apresentado um conjunto de indicadores selecionados e diferenciados por cor/raça e por sexo em tabelas separadas, para facilitar a compreensão dos resultados encontrados. Serão descritas informações para as pessoas que frequentaram o ensino médio nos anos de 1991 e 2010, com as respectivas taxas de variação para o período e a Taxa Líquida de Matrícula ${ }^{21}$ (TLM) para a faixa de 15 a 17 anos e uma "estendida" para 18 e 19 anos (para captar os que estão atrasados na etapa). Esses indicadores ajudam na compreensão dos resultados descritos no Gráfico 4. Deve-se considerar inicialmente que o crescimento populacional no período (para a faixa de 15 a 19 anos) foi de 13,2\%,

\footnotetext{
${ }^{21}$ Calculada pelo número de pessoas que frequentam o ensino médio na idade esperada pela população na idade esperada.
} 
dessa forma, o acesso ao ensino médio teve uma expansão representativa, tanto para o recorte racial como por sexo.

O ensino médio tem ocupado, na última década, uma centralidade maior nas discussões sobre as políticas públicas na área da educação, em especial a partir dos sistemas de avaliação que indicam os baixos resultados observados nos exames de proficiência dos estudantes (Saeb, Enem) e a relação estabelecida entre desenvolvimento social e econômico do país e as condições de escolarização da população. Alguns autores têm refletido sobre os desafios para o ensino médio e as necessidades de mudança na organização dessa etapa de escolarização (Krawazyk, 2011; Brandão, 2011;), porém poucos estudos trazem os marcadores sociais para a discussão (Artes, 2016).

A Tabela 1 apresenta os resultados por cor/raça. As três primeiras linhas indicam os valores absolutos e a taxa de variação para o período. A participação dos brancos, que era de $2 / 3$ em 1991, recua para 46,2\% em 2010, com uma taxa de variação geral de 171,6, indicando uma ampliação de oferta e de acesso. Para os negros, a variação chega a 241,9\%, demonstrando que foi o grupo que passou a acessar o ensino médio com a universalização do ensino fundamental nas décadas de 1980 e 1990. Vale comentar que, no relatório de 1986, a condição de escolarização de negros no ensino médio estava presente em apenas uma tabela, que trazia informações de pessoas que, em 1982, com 7 anos ou mais, frequentaram o $2^{\circ}$ e $3^{\circ}$ grau $^{22}$ por cor/raça para o estado de São Paulo: a taxa para brancos era de $25,1 \%$ e para negros, $8,2 \%$

Os diferenciais por cor/raça ficam mais explícitos na análise da TLM: em 1991, apenas 8,4\% dos negros de 15 a 17 anos estavam no ensino médio, índice que chega a 41,4\% em 2010. A utilização de uma TLM estendida para 18 e 19 anos visa a mostrar que uma parte dos jovens, em especial os negros, está no ensino médio em uma idade mais avançada, realidade para perto dos $20 \%$ de negros entre os 18 e 19 anos.

Tabela 1. Indicadores de acesso e taxa liquida de matrícula para o Ensino Médio por cor/raça. Brasil

\begin{tabular}{|c|c|c|c|c|c|}
\hline \multirow{2}{*}{} & \multicolumn{2}{|c|}{1991} & \multicolumn{2}{|c|}{2010} & Variação \\
\cline { 2 - 5 } & $\mathrm{N}$ & $\mathbf{\%}$ & $\mathrm{N}$ & $\mathbf{\%}$ & $\%$ \\
\hline
\end{tabular}

${ }^{22}$ Nomenclatura usada para ensino médio e ensino superior.

Revista da ABPN • v. 11, Ed. Especial - Caderno Temático: Raça Negra e Educação 30 anos depois: e agora, do que mais precisamos falar? • abril de 2019, p.32-64

DOI 10.31418/2177-2770.2019.v11.c.1.p32-64 


\begin{tabular}{|l|r|r|r|r|r|} 
Brancos & 2.051 .812 & $\mathbf{6 2 , 8}$ & 4.101 .430 & $\mathbf{4 6 , 2}$ & $\mathbf{9 9 , 8}$ \\
\hline Negros & 1.180 .662 & $\mathbf{3 6 , 1}$ & 4.037 .100 & $\mathbf{4 5 , 5}$ & $\mathbf{2 4 1 , 9}$ \\
\hline Total & 3.267 .698 & & 8.875 .556 & & $\mathbf{1 7 1 , 6}$ \\
\hline \multicolumn{5}{|c|}{ TLM (15-17 anos) } \\
\cline { 1 - 3 } \\
\cline { 1 - 3 } Brancos & 23,6 & 55,4 & \\
\cline { 1 - 4 } Negros & 8,4 & 41,4 & \\
\hline Brancos & 16,8 & 16,1 & \\
\hline Negros & 10,8 & 19,9 & \\
\hline
\end{tabular}

Fonte: Organizado pelas autoras com base nos dados do IBGE, BME, Censo Demográfico 1991 e 2010.

De forma complementar, a Tabela 2 apresenta os resultados no recorte de sexo. As mulheres, que já eram maioria no ensino médio em 1991, mantêm esse quadro, com uma variação um pouco maior para os homens: 191,4\% contra 156,7\%. A TLM indica que a ampliação no acesso não mudou o diferencial entre homens e mulheres. Na análise para a TLM estendida (18 a 19 anos), a maior participação dos meninos em 2010 pode ser um indicativo de que as trajetórias de escolarização são um pouco mais tumultuadas e que repercute na maior presença ainda no ensino médio, em idade acima da esperada.

Tabela 2. Indicadores de acesso e taxa liquida de matrícula para o Ensino Médio por sexo. Brasil

\begin{tabular}{|c|c|c|c|c|c|}
\hline & \multicolumn{2}{|l|}{1991} & \multicolumn{2}{|l|}{2010} & \multirow{2}{*}{$\begin{array}{c}\text { Variação } \\
\%\end{array}$} \\
\hline & $\mathrm{N}$ & $\%$ & $\mathrm{~N}$ & $\%$ & \\
\hline Homens & 1.403 .036 & 42,9 & 4.088 .580 & 46,1 & 191,4 \\
\hline Mulheres & 1.864 .662 & 57,1 & 4.786 .976 & 53,9 & 156,7 \\
\hline Total & 3.267 .698 & & & & 171,6 \\
\hline \multicolumn{5}{|c|}{ TLM (15-17 anos) } & \\
\hline Homens & \multicolumn{2}{|c|}{13,2} & \multicolumn{2}{|l|}{42,4} & \\
\hline Mulheres & \multicolumn{2}{|l|}{18,2} & \multicolumn{2}{|l|}{52,2} & \\
\hline \multicolumn{5}{|c|}{ TLM (18 a 19 anos) } & \\
\hline Homens & \multicolumn{2}{|c|}{12,2} & \multicolumn{2}{|l|}{18,5} & \\
\hline Mulheres & \multicolumn{2}{|l|}{15,3} & \multicolumn{2}{|l|}{17,9} & \\
\hline
\end{tabular}


Fonte: Organizado pelas autoras com base nos dados do IBGE, BME, Censo Demográfico 1991 e 2010.

Dessa forma, pode-se concluir que o acesso ao ensino médio tem uma marca de gênero tão importante quanto as desigualdades raciais: são os meninos e os negros que estão menos no ensino médio. Considerando que é uma etapa de frequência obrigatória (pós-Emenda Constitucional n. 59), está posto o desafio para os estados para o cumprimento da norma legal.

O último conjunto de dados apresentados para o ensino médio procura fazer a relação entre a condição de estudante e a necessidade de inserção no mercado de trabalho. A leitura dos gráficos deve considerar a porcentagem dentro de cada subgrupo, isto é, no Gráfico 5, para cada grupo de 100 homens brancos que frequentam o ensino médio, $45 \%$ estudam e trabalham e $55 \%$ só estudam, e assim sucessivamente para os outros censos.

Os resultados para os estudantes no ensino médio indicam uma diminuição na associação estudo e trabalho nos 30 anos pesquisados, com uma maior participação dos homens e sem diferença representativa por cor/raça. Essa queda pode ser explicada (hipótese a ser verificada em outros estudos) pelo fator idade: com a regularização do fluxo escolar, um contingente mais novo de jovens acessaram o ensino médio, mantendo-se ainda afastados do mercado de trabalho.

Gráfico 5. Pessoas que frequentam o Ensino Médio e trabalham por sexo e cor/raça. Brasil

\begin{tabular}{|r|r|r|}
\hline \multicolumn{4}{|c|}{ Ensino Médio (Trab e Est) } \\
100 \\
80 \\
60 \\
40 \\
20 \\
0
\end{tabular}

Fonte: Organizado pelas autoras com base nos dados do IBGE, BME, Censo Demográfico 1991, 2000 e 2010 


\section{ENSINO SUPERIOR}

No Gráfico 6, temos a distribuição para os que finalizaram o ensino superior. Para esse nível de escolaridade, os diferenciais por cor/raça estão bem demarcados. Para um número esperado de $25 \%$ de homens negros, esse valor está em 11,3\%. A maior participação é para mulheres brancas: 40,7\%. Dentro dos grupos de cor, os indicadores para as mulheres são superiores aos homens, tanto para as mulheres brancas como para as mulheres negras.

\section{Gráfico 6. Etapa mais elevada concluída, Ensino Superior por sexo e cor/raça. Brasil}

\begin{tabular}{|c|c|c|c|}
\hline \multicolumn{4}{|c|}{ Ensino Superior } \\
\hline \multirow{2}{*}{$\begin{array}{r}50 \\
40 \\
30 \\
20 \\
10 \\
0\end{array}$} & & & \\
\hline & 1991 & 2000 & 2010 \\
\hline Homem Branco & 41,8 & 39,4 & 32,8 \\
\hline Mulher Branca & 42,5 & 44,8 & 40,7 \\
\hline Homem Negro & 7,8 & 7,3 & 11,3 \\
\hline Mulher Negra & 7,9 & 8,5 & 15,2 \\
\hline
\end{tabular}

Fonte: Organizado pelas autoras com base nos dados do IBGE, BME, Censo Demográfico 1991, 2000 e 2010.

Esse quadro é alterado de forma mais premente entre os anos de 2000 e 2010, com uma maior participação (ainda distante do esperado) para os negros no acesso ao ensino superior. A taxa de variação entre 2000 e 2010 é de 70,3\% para o total de graduados, ficando em $164,3 \%$ para os homens negros e $204,4 \%$ para as mulheres negras.

O Gráfico 7 apresenta os resultados para o público que frequenta o ensino superior. Se, no intervalo entre 1991 e 2000, as distâncias entre os grupos mantiveramse estáveis, as mudanças são observadas no intervalo entre os anos de 2000 e 2010. Vale ressaltar que foi nessa década que as políticas de ação afirmativa adentraram as Instituições de Ensino Superior, garantindo mais equidade e maior acesso para pretos, pardos e indígenas nos cursos de graduação (Artes; Ricoldi, 2015; Feres; Daflon, 2013). Enquanto o crescimento geral é de 360,9\% para o intervalo de 1991 a 2010, para os homens negros esse índice alcança $643,4 \%$ e para as mulheres negras, $741,4 \%$. Se o 
acesso ao ensino superior tem uma marca racial, dentro dos grupos por sexo, as mulheres estão à frente dos homens. Esse resultado deve ser relacionado às maiores taxas de finalização do ensino médio, condição necessária para frequência ao ensino superior.

Gráfico 7. Pessoas que frequentam a escola, Ensino Superior por sexo e cor/raça. Brasil

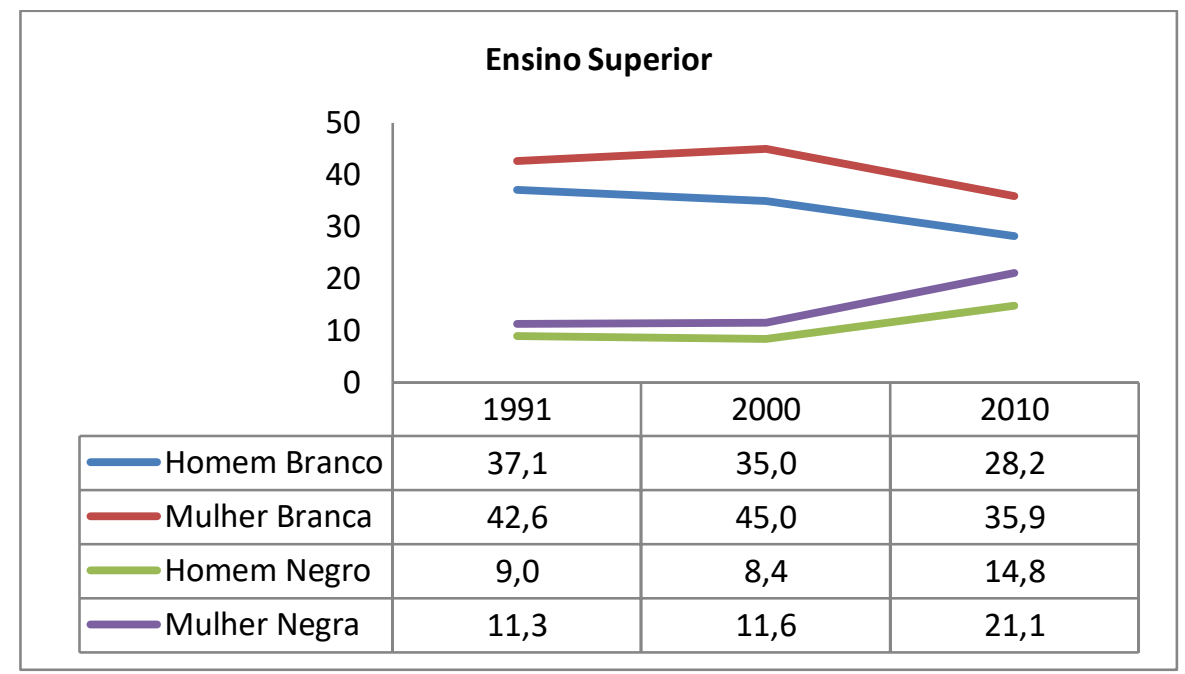

Fonte: Organizado pelas autoras com base nos dados do IBGE, BME, Censo Demográfico 1991, 2000 e 2010.

De forma complementar, o Gráfico 8 relaciona a condição de ser estudante de graduação e estar trabalhando.

Gráfico 8. Pessoas que frequentam o Ensino Superior e trabalham por sexo e cor/raça. Brasil

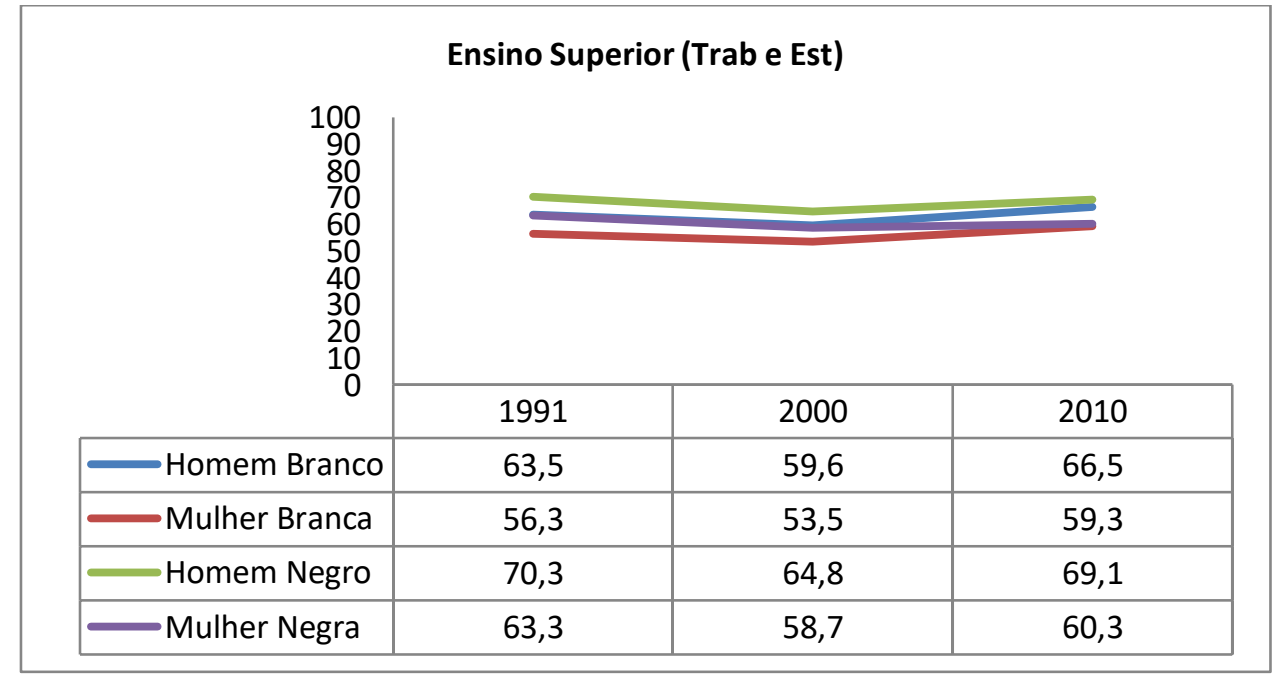

Fonte: Organizado pelas autoras com base nos dados do IBGE, BME, Censo Demográfico 1991, 2000 e 2010 . 
Para análise, as marcas de cor/raça também se fazem presentes, com os homens negros e as mulheres negras com maior associação estudo e trabalho. O quadro não se alterou nos 30 anos pesquisados: próximo de $70 \%$ dos jovens que estão no ensino superior associam estudo e trabalho. Considerando que $75 \%$ das matrículas no Brasil ocorrem em instituições de ensino superior (IES) privadas (Ristoff, 2016), o resultado para associação estudo e trabalho está em consonância com a necessidade dos jovens em financiar seus próprios estudos.

\section{GARGALOS E DESAFIOS}

Muitas escolhas foram feitas para a construção deste texto: a centralidade em informações por sexo e cor/raça e o predomínio de dados sobre o ensino médio e superior foram definidos para procurar dar vazão às discussões sobre as ocupações nos espaços de escolarização em evidência na atualidade. A finalização da educação básica e obrigatória e o acesso aos cursos de graduação são apresentados como condição necessária para a inserção produtiva dos jovens na sociedade tecnológica e de informação do século XXI. Esse bem social não tem sido distribuído de forma equitativa entre os grupos, em especial para os homens e em uma maior escala para os negros. Esse texto quis ressaltar tal condição.

Porém a comparação, mesmo que bastante limitada, com os dados produzidos no relatório de 1986, indica que muitos avanços foram feitos, também para os negros no acesso à escolarização formal no Brasil. Se, em 1986, a realidade era o não acesso às séries iniciais da educação básica, nos processos de entrada na trajetória da escolarização, para todos, mas de forma mais intensa para os meninos negros, na atualidade o acesso às séries iniciais está próxima da universalização e os gargalos concentram-se no ensino médio e na passagem para o ensino superior, ainda mais difícil para os meninos negros.

Será essa a realidade vivida? Em todos os cantos de nosso país? Apesar da melhora significativa nos indicadores educacionais, em regiões mais distantes e em condições específicas (comunidades indígenas e/ou quilombolas), o quadro ainda se aproxima do descrito há 30 anos passados. Faz-se necessário estudar, refletir e propor 
mudanças nas políticas públicas que agreguem ações específicas para esses grupos minoritários.

Ao finalizar a apresentação do relatório de 1986, as autoras destacam uma condição:

Finalmente, mencionamos a necessidade de continuarmos a investigação, apenas iniciada no contexto desse diagnóstico, sobre os determinantes do pequeno, ou quase ausente interesse de pesquisadores e educadores sobre a educação de negros. Esta investigação poderá desvelar pistas para que se empreenda uma ação de sensibilização junto à academia. (Rosemberg et al, 1986, p. iv)

Pode-se afirmar que a academia está mais sensibilizada para essa realidade, vide o número de publicações, estudos, dissertações e teses que desvelam as condições de desigualdades e de racismo vivenciados nos espaços escolares e de saberes. Da mesma forma, a sociedade civil, a partir de um conjunto de organizações, coletivos e grupos, tem explicitado, apresentado e proposto ações que visam a alterar as situações de desigualdades observadas, em especial, para os negros.

A interface sexo e cor/raça para a apresentação dos resultados é apenas inicial e descritiva. Fazem-se necessárias novas reflexões sobre o sentido dos piores indicadores encontrados para os meninos negros. Como a escola tem atuado e construído tal realidade?

As diferenças regionais e a distribuição racial por região são outros fatores que merecem novos estudos. Até que ponto os piores indicadores observados para os negros são influenciados pela menor oferta de escolarização, em especial para o ensino superior em regiões em que são maioria (em especial no Norte e no Nordeste)?

Enfim, velhas discussões continuam em pauta: os piores indicadores educacionais encontrados para os negros. Assim como novas reflexões e estudos devem ser construídos: como superar um modelo de escolarização que tem por padrão um aluno branco, de classe média e, portanto, distante da realidade vivenciada por parte significativa de nossa população? Como garantir um acesso equitativo e de qualidade em especial para os meninos e os negros? E para os meninos negros? 
A leitura do relatório de 1986 e a apresentação de dados dos três últimos censos indicam que mudanças significativas ocorreram no acesso e frequência à escola para todos, mas ainda de forma muito desigual para os negros. São as mulheres brancas que apresentam as melhores condições, estando os homens negros no outro extremo. Novos estudos, reflexões e pesquisas ainda precisam ser feitas para compreender tal realidade. Condição necessária para que as mudanças com vistas à desejada equidade no acesso a todos os bens sociais e em especial à educação ocorram de forma concreta.

Este estudo só foi possível pelo acesso a bases de dados via microdados e/ou plataformas on-line de informações quantitativas. Tal facilidade, aparentemente impensável nos anos de 1980, deve servir de incentivo a um novo conjunto de perguntas e respostas para que se alcance a desejada educação de qualidade e para todos, todos mesmo!

\section{REFERÊNCIAS}

ARTES, Amélia Cristina Abreu. O ensino médio como filtro para o acesso de negros no ensino superior brasileiro. Revista da Associação Brasileira de Pesquisadores/as Negros/as (ABPN), [S.1.], v. 8, n. 19, p. 34-51, jun. 2016.

ARTES, Amélia; RICOLDI, Arlene Martinez. Acesso de negros no ensino superior: o que mudou entre 2000 e 2010. Cadernos de Pesquisa, São Paulo, v. 45, n. 158, p. 858-881, 2015.

ARTES, Amelia Cristina Abreu. O ensino médio como filtro para o acesso de negros no ensino superior brasileiro. Revista da Associação Brasileira de Pesquisadores/as Negros/as (ABPN), [S.1.], v. 8, n. 19, p. 34-51, jun. 2016.

BRANDÃO, Carlos Alberto. O ensino médio no contexto da Plano Nacional de Educação: o que ainda precisa ser feito. Cadernos Cedes, Campinas, v. 31, n. 84, p. 195-208, maio-ago. 2011.

BELTRÃO, Kaizo; TEIXEIRA, Moema de P. O vermelho e o negro: raça e gênero na universidade brasileira - uma análise da seletividade das carreiras a partir dos censos demográficos de 1960 a 2000. Texto para discussão, RJ, IPEA, outubro de 2004.

BEOZZO, José Oscar. Situação do negro na sociedade brasileira. Petrópolis: Vozes, 1983. CARNEIRO, Sueli; SANTOS, Thereza; DE OLIVEIRA COSTA, Albertina. Mulher negra: política governamental e a mulher. São Paulo Conselho Estadual da Condição Feminina, 1985.

CDES. As desigualdades na escolarização no Brasil: relatório de observação $\mathrm{n}^{\circ}$ 5. Brasília: Presidência da República, Conselho de Desenvolvimento Econômico e Social - CDES, 2014.

CRENSHAW, Kimberlé. Documento para o encontro de especialistas em aspectos da discriminação racial relativos ao gênero. Estudos feministas, v. 10, n. 1, p. 171, 2002. 
CUNHA, Estela Maria Garcia Pinto. Brasil está reduzindo suas disparidades raciais? XVIII, ABEP, 2012.

FRANCO, Creso; ALVES, Fátima; BONAMINO, Alicia. Qualidade do ensino fundamental: políticas, suas possibilidades, seus limites. Educação \& Sociedade, v. 28, n. 100, 2007.

FERES JR, João, DAFLON, Verônica. As políticas de ação afirmativa nas universidades estaduais. Rio de Janeiro GEMMA, 2013.

FIBGE, Bases de dados. Metadados. INEP. Censo da Educação Superior. 2013 Disponível em: $<$ http://ces.ibge.gov.br/base-de-dados/metadados/inep/censo-da-educacao-superior>. Acesso em: 23 out. 2013 .

GUIMARÃES, Antônio Sergio. Classes, raças e democracia. São Paulo: Ed. 34, 2002.

HASENBALG, Carlos; GONZALES, Lelia. Lugar de negro. Rio de Janeiro: Marco Zero, 1982.

INEP. Apresentação do sistema e-mec. 2017 Disponível em: <http://portal.mec.gov.br/e-mecsp-257584288>. Acesso em: 15 set. 2017.

INSTITUTO DE PESQUISA ECONÔMICA APLICADA - IPEA. Situação social da população negra por estado. Secretaria de Políticas de Promoção da Igualdade Racial. Brasília: Ipea, 2014.

INSTITUTO DE PESQUISA ECONÔMICA APLICADA - IPEA. Retrato das desigualdades de gênero e raça / Instituto de Pesquisa Econômica Aplicada - 4. ed. Brasília: Ipea, 2011.

HENRIQUES, Ricardo. Desigualdade racial no Brasil: evolução das condições de vida na década de 90. 2001

HIRATA, Helena. Gênero, classe e raça: Interseccionalidade e consubstancialidade das relações sociais. Tempo social, v. 26, n. 1, p. 61-73, 2014.

KRAWAZYK, Nora. Reflexões sobre alguns desafios do ensino médio no Brasil. Cadernos de Pesquisa, São Paulo, v. 41, n. 144, jan/abril 2011.

KERGOAT, Danièle. Dinâmica e consubstancialidade das relações sociais. Novos EstudosCEBRAP, n. 86, p. 93-103, 2010.

KUENGER, Acácio. O ensino médio no Plano Nacional de Educação: 2011-2020: superando a década perdida? Educ. Soc., Campinas, v. 31, n. 112, p. 851-873, jul.-set. 2010.

LIMA, Leonardo Claver Amorim. Da universalização do ensino fundamental ao desafio de democratizar o ensino médio em 2016: o que evidenciam as estatísticas? Revista Brasileira de Estudos Pedagógicos, v. 92, n. 231, 2011.

McCLINTOCK, Anne. Imperial Leather: Race, Gender, and Sexuality in the Colonial Contest. New York: Routledge, 1995.

NOGUEIRA, Oracy. Preconceito racial de marca e preconceito racial de origem: sugestão de um quadro de referência para a interpretação do material sobre relações raciais no Brasil. Tempo social, v. 19, n. 1, p. 287-308, 2007. 
OLIVEIRA, Jane Souto de. Brasil mostra a tua cara": imagens da população brasileira nos censos demográficos de 1872 a 2000. Rio de Janeiro: Ministério do Planejamento, Orçamento e Gestão, 2001.

OLIVEIRA, Romualdo Portella de Da universalização do ensino fundamental ao desafio da qualidade: uma análise histórica. Educação \& Sociedade, v. 28, n. 100, 2007.

OSORIO, Rafael Guerreiro. O sistema classificatório de cor ou raça do IBGE.Rio de Janeiro, IBGE 2003.

PAIXÃO, Marcelo (Org). Relatório Anual das Desigualdades Raciais no Brasil: 2007-2008. Rio de Janeiro UERJ, 2008.

PAIXÃO, Marcelo (Org). Relatório Anual das Desigualdades Raciais no Brasil: 2009-2010. Rio de Janeiro UERJ, 2010.

PISCITELLI, Adriana. Interseccionalidades, categorias de articulação e experiências de migrantes brasileiras. Sociedade e Cultura, v. 11, n. 2, 2008.

PIZA, Edith; ROSEMBERG, Fúlvia. Cor nos censos brasileiros. Revista USP, n. 40, p. $122-$ 137, 1999.

PETRUCCELLI, José Luis. Ethnic/racial statistics: Brazil and an overview of the Americas. In: FERRÁNDEZ, L. F. A.; KRADOLFER, SEverlasting countdowns: race, ethnicity and national censuses in Latin American states. Newcastle: Cambridge, 2012. p. 264-303.

RISTOFF, Dilvo. Democratização do Campus: impacto dos programas de inclusão sobre o perfil da graduação. Cadernos do GEA, n. 9, Rio de Janeiro: FLACSO, GEA, UERJ, LPP, janjun 2016.

ROSEMBERG, Fúlvia. Educação formal, mulher e gênero no Brasil contemporâneo. Revista Estudos feministas, Florianópolis, n. 2,2001.

ROSEMBERG, Fúlvia; ARTES, Amélia. O rural e o urbano na oferta de educação para crianças de até 6 anos. In: BARBOSA, Maria Carme (et al)? Oferta e demanda de educação infantil no campo. Porto Alegre: Evangraf, 2012. p. 13-69.

ROSEMBERG, Fúlvia; PINTO, Regina Pahim. Educação da mulher São Paulo, Nobel, 1985.

ROSEMBERG, Fúlvia; MADSEN, Nina., Educação formal, mulheres e gênero no Brasil contemporâneo. In: BARSTED, Leila L; PITANGUY, Jacqueline (Org) O Progresso das Mulheres no Brasil 2003-2010 / Rio de Janeiro: CEPIA; Brasília: ONU Mulheres, 2011. p. 390424.

ROSEMBERG, Fúlvia et al. Diagnóstico sobre a situação educacional de negros (pretos e pardos) no Estado de São Paulo. (Relatório preliminar). São Paulo. Fundação Carlos Chagas, v. 1 e v. 2, 1986 (mimeo).

SAMPAIO, Carlos Eduardo Moreno. A situação educacional dos jovens brasileiros na faixa etária de 15 a 17 anos. 2009 Disponível em: www.ipea.gov.br Acesso em: setembro de 2017. 
SENKEVICS, Adriano; MACHADO, Tatiana; OLIVEIRA, Adolfo. A cor ou raça nas estatísticas educacionais: uma análise dos documentos de pesquisa do INEP. Brasília: Inep, 2016.

SILVA, Nelson do Valle; HASENBALG, Carlos. Tendências da desigualdade educacional no Brasil. Dados [online]. v. 43, n. 3, 2000.

SOARES, Sergei. A demografia da cor: a composição da população brasileira de 1890 - 2007. In: THEODORO, Mario (org.) As políticas públicas e a desigualdade racial no Brasil: 120 anos após a abolição, IPEA, 2008.

SOUZA, Pedro Herculano Guimarães Ferreira de. A distribuição de renda nas pesquisas domiciliares brasileiras: harmonização e comparação entre Censos, PNADs e POFs. 2013.

SULIANO, Daniel Cirilo; SIQUEIRA, Marcelo Lettieri. Retornos da educação no Brasil em âmbito regional considerando um ambiente de menor desigualdade. Econ. Apl., Ribeirão Preto, v. 16, n. 1, p. 137-165, mar. 2012. 